\title{
Relaciones humanas de calidad como contexto de salud y libertad'
}

\section{Sandra Racionero-Plaza ${ }^{2}$}

Resumen: Este artículo, basado en el texto de la lección inaugural del curso 2017-2018 de la Universidad Loyola Andalucía, profundiza en una de las líneas de investigación prioritarias en psicología y neurociencia a nivel internacional: el impacto de la calidad de las relaciones humanas en la salud y en la mejora social. Bajo el título: "Relaciones humanas de calidad: contexto de salud y libertad" se comparten los principales hallazgos científicos centrados en cómo las relaciones humanas violentas perjudican la salud mental y física, incluso el desarrollo cerebral, y cómo, al contrario, las relaciones humanas de calidad como la amistad, garantizan un desarrollo cognitivo y emocional integral, saludable y positivo no sólo para uno mismo sino también para la humanidad.

Palabras clave: relaciones humanas, violencia de género, memoria, sentimientos, neurociencia, amistad.

Fecha de recepción: 17 de octubre de 2017.

Fecha de admisión definitiva: 25 de octubre de 2017.

1 El texto del presente artículo es, en gran medida, el de la lección inaugural del curso académico 2017-2018 de la Universidad Loyola Andalucía, pronunciada por la autora el 11 de septiembre de 2017.

2 Universidad Loyola Andalucía. Departamento de Psicología. Investigadora Ramón y Cajal. 


\section{Quality human relations as a context of freedom}

Abstract: This article, based on the text of the inaugural lecture of the school year 20172018, of the Andalusia Loyola University, studies in depth one of the main research lines in psychology and neuroscience at international level: the impact of the human relations on the health and on the social improvement. Under the title "Quality human relations as the context of freedom", are shared the main scientific findings centered on how the violent human relations hurt the mental and physical health, included the cerebral development; and how, on the contrary, the outstanding human relations, free of violence, as the friendship, guarantee a development cognitive and emotional that is integral, healthy and positive, not only for oneself, -both he and she-, but also for the whole of humanity.

Keywords: Human relations, gender violence, memory, feelings, neuroscience, friendship.

\section{Relations humaines de qualité comme contexte de liberté}

Résumé: Cet article, basé sur le texte de la leçon inaugurale de l'année 2017-2018 de I'Université Loyola Andalousie, approfondit I'un des domaines de recherche prioritaires en psychologie et en neuroscience au niveau international: I'impact de la qualité des relations humaines sur la santé et sur l'avancée sociale. Sous le titre: "Relations humaines de qualité comme contexte de liberté» sont partagés les principales trouvailles scientifiques centrées sur le fait que les relations humaines violentes sont préjudiciables pour la santé mentale et physique, même pour le développement cérébral, et comment, au contraire, les relations humaines de qualité, libres de violence comme l'amitié, garantissent un développement cognitif et émotionnel intégral, sain et positif non seulement pour nous-mêmes mais aussi pour l'humanité.

Mots clé: Relations humaines, violence à caractère sexiste, mémoire, sentiments, neuroscience, amitié.

\section{El giro de la ciencia psicológica: poniendo en el centro los principales retos al desarrollo humano saludable}

La psicología ha cambiado enormemente en las últimas décadas. Científicos y científicas con una gran combinación de excelencia científica y excelencia humana han sido centrales en iniciar cambios que han dado un nuevo rumbo a la ciencia psicológica. Entre ellos, se encuentra Jerome Bruner (1915-2016), a quien especialmente admiro por su combinación de conocimiento científico, compromiso humano y conducta ética.

Jerome Bruner fue el líder de la revolución cognitiva en psicología, movimiento que consistió en reivindicar, frente al conductismo, el papel de la mente y de los procesos cognitivos no observables en la explicación de la conducta humana. Bruner $(1974,1990)$ tuvo un papel central en el desarrollo de las teorías acerca de cómo 
la mente procesa la información, arrojando una nueva luz sobre qué actividades simbólicas las personas llevamos a cabo para dotar de sentido no solo al mundo, sino también a nosotros mismos.

Sin embargo, a mediados de los años 90 , Bruner sorprendió a la comunidad científica internacional informando que cambiaba su enfoque teórico. En el libro The culture of education (Bruner, 1996) comunicaba que pasaba de visiones más cognitivistas, de corte más individualista e intrapsicológico, a una visión de la psicología más cultural, centrada en el estudio de lo que ocurre en el plano intersubjetivo. En el capítulo 9 de ese libro afirmaba que "la intersubjetividad es el siguiente capítulo de la psicología", indicando que la ciencia psicológica no tenía futuro fuera del estudio de la interacción humana y del contexto cultural que dan forma a la mente. Bruner apelaba a cómo un enfoque excesivamente intrapsicológico no estaba resultando efectivo para solucionar los problemas centrales de niños, jóvenes y personas adultas, de naturaleza social y con claras implicaciones psicológicas. Ese capítulo anunciaba el giro intersubjetivo y narrativo que la psicología iba a empezar a vivir.

Ese nuevo rumbo ha alcanzado incluso la vertiente de la psicología que habría parecido más resistente al mismo, la psicología dedicada al estudio de procesos cognitivos como la memoria (Hirsty Rajaram, 2014). El acuerdo es ya generalizado en que la actividad mental es de naturaleza contextualizada y, por tanto, cualquier investigador 0 investigadora que pretenda entender completa y profundamente la mente y la conducta es necesario que tenga en cuenta los factores sociales y el contexto cultural que dan forma a la mente. Lo esencial en las personas no puede entenderse sin ese escenario.

Esta nueva mirada ha supuesto que las y los investigadores en psicología salgan de sus despachos y de sus laboratorios para prestar atención, en primer lugar, a lo que ocurre en la vida cotidiana de personas corrientes en multitud de lugares. ¿Qué es lo que preocupa a individuos y grupos en su día a día? ¿Cuáles son sus principales obstáculos para un desarrollo saludable y libre?

\section{Aumento de la violencia en las relaciones humanas: un pa- norama estremecedor}

De entre esas trabas al desarrollo humano hay una de creciente importancia a la que la ciencia psicológica atiende desde los diferentes ámbitos de nuestra disciplina: la violencia. 
Veamos una historia real. Amanda Todd era una estudiante canadiense de 15 años que acabó por quitarse la vida después de una campaña en internet de acoso sexual y "bullying" que duró tres años. Después de interaccionar "online" con un hombre, éste le pidió imágenes íntimas. Aunque dudó y no le gustaba, finalmente Amanda le envío una. Sin el permiso de la joven, ese hombre difundió la foto en "facebook", concretamente entre los compañeros y compañeras de Amanda. Cuando ella llegó al instituto, fue consciente de lo que ocurría, pero no porque sus amigas y amigos le explicaran lo sucedido y se pusieran de su lado sino porque la empezaron a acosar insultándola sin límite. Esos mismos iguales se sumaron a la campaña de acoso por las redes sociales. A pesar de los intentos de la familia por proteger a Amanda, incluido el cambiar de lugar de vivienda, el acosador la perseguía y proseguía el acoso.

Ante la violencia de sus iguales y la falta de apoyo de otras personas adultas, Amanda acabó pidiendo ayuda a la ciudadanía mundial, subiendo vídeos en "youtube" donde explicaba lo que le ocurría en busca de solidaridad: "No tengo a nadie. Necesito a alguien" decía en sus últimos mensajes en internet. Suplicaba amistad. La violencia que recibía, unida a la falta de respuesta social hizo que la situación fuera insoportable psicológicamente. Al poco tiempo, Amanda se suicidó.

Este caso conmocionó al mundo, tuvo mucho impacto en los medios y alertó del tipo de problemas de las y los adolescentes en nuestra sociedad actual y que merecen pasar a primer plano en las agendas de investigación de las y los psicólogos.

El panorama es estremecedor. Las estadísticas indican que el número de víctimas de violencia virtual y presencial crece a una velocidad de vértigo en todo el mundo. En Europa, en el 2011 , un 6\% de infancia europea de entre 9 y 16 años sufrieron acoso "online", y un 3\% lo ejercieron (Dalla Pozza et al, 2016). En el 2010, un $7 \%$ de niñas y niños de entre 11 y 16 años fueron ciberacosados, mientras que en el 2014 esa cifra ascendió al 12\% (Dalla Pozza et al, 2016). Y, hay víctimas porque hay agresores, también en la infancia y en la adolescencia. El análisis internacional de UNICEF (2014) Hidden in plain sight indicó que en la mayoría de los países, más de un 30\% de adolescentes de entre 11 y 15 años encuestados admitieron haber ejercido "bullying" en el centro educativo en los últimos dos meses. Ante esta realidad, la preocupación de organismos internacionales sobre el aumento de la violencia entre las personas jóvenes es creciente.

Pero existe una violencia que nos resulta cada día más alarmante no solo por la celeridad de su aumento sino también por el descenso en la edad de las víctimas. En un informe de la Organización Mundial de la Salud (OMS, WHO) se mostraba 
que la violencia de género era ya en el 2010 la principal causa de muerte entre las mujeres de entre 15 y 44 años en todo el mundo, por delante de la suma de las muertes provocadas por el cáncer, los accidentes de tráfico y las guerras. La violencia de género es un problema de salud global de proporciones epidémicas. Superando algunas falsas ideas, las evidencias indican que esta violencia se encuentra en todas las clases sociales y culturas, y en todo tipo de relaciones afectivo-sexuales, sean estables o esporádicas, siendo especialmente relevantes el segundo tipo en el caso de la adolescencia y las primeras experiencias íntimas. A nivel internacional, el $30 \%$ de mujeres entre 15 y 19 años sufren o han sufrido violencia en sus relaciones afectivo-sexuales (WHO, 2015) y 1 de cada 3 adolescentes de 15 años de edad ha sufrido violencia física o sexual (EUROPEAN UNION Agency fOr Fundamental Rights - FRA, 2014).

Según definición de las Naciones Unidas (1993), definición que se utiliza como referente en la mayoría de la investigación mundial sobre el tema, es violencia de género cualquier acto que resulta en o es probable que resulte en daño o sufrimiento físico, sexual o psicológico en la mujer, incluyendo las amenazas de perpetrar dichos actos, coerción o privación arbitraria de libertad, ocurra esto tanto en espacios públicos como privados.

En la "base del iceberg" de esta violencia se encuentran relaciones afectivo sexuales estables o esporádicas donde tiene lugar la humillación, el desprecio, el engaño y la coacción. La investigación científica sobre este tema publicada en revistas de primer decilo del JCR, como Violence Against Women, ha demostrado que entre las causas de la violencia contra las mujeres se encuentra un modelo de socialización dominante para muchas niñas y adolescentes en el que la atracción afectivo-sexual se vincula a la violencia (Valls et al, 2008). Literatura como El perfume, películas como Tres metros sobre el cielo, o canciones de cantantes como Rihanna, son solo algunos ejemplos de estímulos en los que se encuentra ese tipo de socialización: libros, películas y canciones que presentan como más atractivo o deseable un tipo de masculinidad tradicional dominante que puede tener conductas violentas (Gómez, 2004). En un lenguaje más cercano, hablamos del "chico malo". Al mismo tiempo, ese modelo dominante vacía de atractivo a un tipo de masculinidad más igualitaria. Como producto de la experiencia con esos medios de socialización y otros agentes, es fácil que algunas jóvenes se socialicen en ese modelo dominante e internalicen esa asociación.

La investigación en psicología del desarrollo y de la personalidad, así como en criminología y estudios de género ya ha aportado evidencias empíricas que apoyan la fuerza explicativa del modelo de socialización dominante como una de las 
causas de la violencia de género. Por ejemplo, algunos resultados impactantes publicados en revistas científicas señalan que los actos delictivos pueden aumentar las citas de los delincuentes (Rebellon y Manasse, 2004), así como un inicio en ese tipo de relaciones incrementa la posibilidad para una adolescente o mujer adulta de tener relaciones estables o esporádicas de tipo abusivo (Bukowski, Sippola y Newcomb, 2000).

\section{Las relaciones tóxicas deterioran la salud mental y física}

Las consecuencias de relaciones humanas violentas son tremendamente negativas para el desarrollo. Todas las relaciones humanas en las que existe algún tipo de violencia son relaciones tóxicas, ya que son adversas para el desarrollo cognitivo, emocional y social de la persona que las sufre. La investigación científica en psicología ya ha demostrado desde hace años que son las relaciones tóxicas -y no otras cuestiones como el trabajo, desmintiendo con esto muchas ocurrencias- las que producen estrés tóxico. Estudios en los campos de la neurociencia, la psicología, la psiquiatría y otras áreas de la medicina han acumulado evidencias muy sólidas que demuestran que las relaciones violentas perjudican la salud a múltiples niveles.

\section{I. Las relaciones violentas deterioran la salud mental, así como la estructura y la actividad cerebral}

Las estadísticas indican que más de la mitad de las niñas y niños, chicas y chicos en Europa que son víctimas de "bullying" $y$ "ciberbullying" reconocen haber padecido depresión como consecuencia de esa vivencia, un 35\% informa que ha llegado a autolesionarse y un 38\% informa que ha tenido pensamientos de suicidio (Dalla Pozza et al, 2016). Una parte de estos, lo comete. Siguiendo esta línea, una revisión sistemática y análisis recientemente publicado en el World Journal of Psychiatry confirma esas mismas secuelas psicológicas y añade otras como el estrés posttraumático, la ansiedad, los síntomas psicóticos y el pánico (Moore et al, 2017).

En lo referente a la violencia de género, la investigación publicada en revistas científicas de impacto, así como informes de la Organización Mundial de la Salud, indican que las adolescentes y mujeres adultas que son víctimas de abuso y acoso tienden a sufrir algunas de esas mismas consecuencias, además de ansiedad, baja autoestima, irritabilidad, cambios de ánimo, miedo, insomnio y trastornos alimentarios entre otros (Seedat et al, 2003; WHO, 2013). 
En un estudio coordinado por Lídia Puigvert desde la Universidad de Cambridge, hemos investigado sobre los recuerdos autobiográficos de mujeres jóvenes universitarias relativos a relaciones afectivo-sexuales violentas, estables o esporádicas. Los informes escritos de ese recuerdo indicaron que las mujeres participantes eran conscientes del daño mental que esas relaciones les supusieron e incluso les seguían suponiendo en la actualidad (Racionero et al, 2017). Episodios relativos a ansiedad, apatía, depresión o tristeza estaban presentes en sus recuerdos.

Pero los efectos de las relaciones humanas violentas son todavía más profundos. La neurociencia ha demostrado que las relaciones tóxicas también afectan negativamente el desarrollo cerebral. Los increíbles avances en las técnicas de neuroimagen ya han permitido evidenciar que la adversidad producida por el estrés tóxico deteriora la actividad y la arquitectura del cerebro (Shonkoff et al, 2012).

Estudios en este campo han demostrado que en situaciones de estrés tóxico se pierden conexiones neuronales e incluso se produce muerte neuronal en el hipocampo, la principal estructura subcortical encargada de la memoria, y en la corteza prefrontal media, que es el área del córtex cerebral implicada en funciones mentales esenciales para las personas, como la planificación de tareas y la resolución de problemas (Dumann, 2009; Shonkoff et al, 2012).

Es más, la investigación mundial ha evidenciado que la exposición a experiencias estresantes altera el tamaño y la arquitectura neuronal de estructuras subcorticales, muy profundas en el cerebro, como la amígdala, lo que afecta al procesamiento de las emociones (Shonkoff et al, 2012). Estas alteraciones hacen que las víctimas de violencia puedan manifestar disfunciones en el aprendizaje, el recuerdo y otras actividades cognitivas de alto nivel.

En el caso de mujeres que han sufrido abuso sexual, se ha identificado que tienen alterado el funcionamiento del llamado axis hipotalámico-pituitario-adrenal, lo que se concreta frecuentemente en trastornos de ansiedad, insomnio, fatiga y problemas digestivos, entre otros (Seedat et al, 2003). Esto nos conecta con el tercer grupo de impactos negativos de las relaciones tóxicas, los relativos a la salud física.

\subsection{Las relaciones violentas deterioran la salud física}

El estrés tóxico derivado de relaciones humanas violentas deteriora la salud física. Una de las principales vías como se produce este daño es a través del impacto que tienen los estados emocionales en el cuerpo. Una de las evidencias más im- 
pactantes en este ámbito ha sido descrita bajo el concepto de efecto telómero. La investigación desarrollada por Elisabeth Blackburn, galardonada con el premio Nobel en medicina en el año 2009, ha demostrado que los patrones de pensamiento negativo vinculados al estrés pueden dañar los telómeros - partes esenciales del ADN de la célula- produciendo un envejecimiento prematuro de la persona y acortando su vida (Blackburn y Epel, 2017). Las relaciones tóxicas alteran el sistema inmunológico e incrementan los marcadores inflamatorios del organismo, lo que se asocia a enfermedades cardiovasculares, hepatitis vírica, cáncer de hígado, asma, enfermedades respiratorias, dentales y autoinmunes, entre otras (Araújo et al, 2009; Bierhaus et al, 2003).

Debido el impacto de las relaciones violentas en la aparición de enfermedades, las colaboraciones entre la psicología y la medicina son crecientes, apoyando estas investigaciones interdisciplinares una mayor efectividad en el tratamiento de las causas de una gran variedad de enfermedades. Así, cada vez más, las exploraciones diagnósticas contemplan variables de experiencias violentas en el desarrollo porque las mismas explican muchos casos a los que la medicina sola no encontraba explicación. Empiezan a proliferar artículos científicos en medicina que incluyen relatos de médicos que experimentaron un giro en su trayectoria profesional al descubrir a través de la acumulación de casos particulares cómo la experiencia de relaciones violentas y los recuerdos de las mismas -que han sido bloqueados, no trabajados- pueden hacer que algunas enfermedades se vuelvan crónicas (Drossman, 2011).

En la exposición de todas estas consecuencias de las relaciones violentas y, en concreto, de la violencia de género sobre la salud, es urgente prestar mayor atención a una cuestión de profunda importancia humana y creciente objeto de trabajo en la ciencia psicológica. Todas estas evidencias sobre cómo la violencia en las relaciones empeora la salud mental, física y el cerebro no sólo afectan a las mujeres víctimas de violencia de género sino también a sus hijos e hijas expuestos a esa violencia. Las relaciones violentas de los adultos son contextos adversos de desarrollo para niñas, niños y adolescentes (Shonkoff et al, 2012). Este tema es una prioridad de investigación en los centros de investigación sobre la infancia más punteros del mundo, como el prestigioso Center on the Developing Child de la Universidad de Harvard.

El mensaje es claro: El tipo de relaciones que se tienen en cualquier momento de la vida son determinantes, no solo para nosotras y nosotros sino también para las personas que nos rodean. 


\section{Ciencia al servicio de la humanidad. Una psicología para superar la violencia}

Toda la evidencia científica acumulada y resumida anteriormente hace que la superación de la violencia en las relaciones humanas se haya vuelto una prioridad tanto para la sociedad civil mundial como para la comunidad científica internacional. Personas de diferentes culturas, religiones, clases sociales y nacionalidades se encuentran unidas reclamando paz y justicia como contextos de desarrollo saludable. Los programas de investigación de mayor prestigio mundial, como el H2O2O de la Comisión Europea, reflejan esta preocupación, con financiación específica dedicada a la superación de la violencia contra los colectivos más vulnerables, como mujeres, niñas y niños. Las principales asociaciones científicas mundiales en psicología muestran este mismo compromiso.

La ciencia mundial no puede -y muchas personas no vamos- a dar la espalda a este sufrimiento humano. Tenemos ejemplos muy inspiradores de ese compromiso en brillantes científicos y científicas. Rita Levi Montalcini, galardonada con el premio Nobel de neurociencia en el 1985 junto con Stanley Cohen por su descubrimiento del factor de crecimiento, murió con más de 100 años regalándonos una vida dedicada a la ciencia y a la humanidad (Levi-Montalcini, 1988). Cuando en una entrevista en sus últimos años le preguntaban que había sido lo mejor de su vida, Rita, firme e ilusionada, respondía: "ayudar a los demás".

Este compromiso no es solo de personas individuales sino también, y cada vez más, de sociedades científicas enteras. La American Psychological Association (APA) es la asociación científica en psicología con más historia y prestigio internacional y es también un ejemplo excelente de compromiso.

En el preámbulo de su riguroso código ético y de conducta, la APA $(2003,2010,2016)$ señala que "los psicólogos están comprometidos con el aumento del conocimiento científico y profesional sobre la conducta (...)", pero no sólo. Se trata de usar ese conocimiento "para mejorar la condición de los individuos, de las organizaciones y de la sociedad". Así lo refleja la propia misión de la APA: "Avanzar la psicología para beneficiar la sociedad y mejorar la vida de las personas".

"La transformación es posible" y la psicología debe proporcionar a las personas las herramientas científicas para hacer esa transformación realidad. Ese fue el mensaje principal de Antonio Lapuente, presidente de la Asociación Americana de Psicología, en el último congreso de la asociación celebrado en agosto de 2017 en Washington. El diagnóstico de la violencia en las relaciones humanas y 
la explicación de sus causas y consecuencias, aunque necesario, no es suficiente. La sociedad precisa y merece soluciones de éxito y nuestra responsabilidad es investigarlas y aportarlas.

El momento actual no puede ser mejor para el avance de esta misión. Es la era del impacto social de la ciencia (Flecha et al, 2015). El programa marco de investigación de la UE, conocido como H2020, ya se organiza en base a "societal challenges", las investigaciones que se financian deben servir para afrontar con éxito esos retos sociales. La investigación de excelencia es y será aquella que aporte soluciones a los principales problemas humanos, y las universidades y centros de investigación de más prestigio del mundo serán aquellos que puedan demostrar ese impacto social.

Ese compromiso de investigación al servicio de la sociedad nos define como universidad jesuita como afirmó Arrupe en 1973 (Kolvenbach, 2008; Romero Rodríguez, 2007). Para el personal investigador de Universidades de la Compañía de Jesús, se trata de promocionar la justicia a través de la evidencia. En definitiva, de servir a los demás a través de la ciencia, trabajando no sólo por los más vulnerables sino también con ellos y ellas. Ignacio Ellacuría era claro a este respecto:

La universidad debe encarnarse entre los pobres para ser ciencia de los que no tienen ciencia, la voz ilustrada de los que no tienen voz, el respaldo intelectual de los que en su realidad misma tienen la verdad y la razón, pero no cuentan con las razones académicas que justifiquen y legitimen su verdad y su razón (SECRETARIADO PARA LA JUSTICIA SOCIAL Y LA Ecología-Compañía de Jesús, 2014, 29).

Además, como publicaba la revista Science, poner la ciencia al servicio de la humanidad no es una opción sino un derecho (Chapman y Wyndham, 2013). El artículo 27 de la Declaración universal de los derechos humanos (1948) ya indica que toda persona tiene derecho a beneficiarse del progreso científico.

En el caso de la psicología y la neurociencia, la investigación más básica, que ha sido muy influyente históricamente, está fundamentando otras investigaciones con impacto social directo sobre la superación de la violencia en las relaciones humanas. Esa investigación es importante. Pero es creciente el número de estudios incluso en áreas como la psicología cognitiva que se orientan al impacto social y examinan la eficacia de ciertas intervenciones de prevención y superación de la violencia, o son las propias investigaciones las que aportan nuevos modelos de intervención social y clínica. La priorización de estos dos últimos tipos de investigación queda reflejada en la creciente representación de las mismas en las revistas científicas de primer nivel mundial. Veamos algunos de esos hallazgos científicos. 
Una de las evidencias de la psicología y la neurociencia que es más relevante para la superación de las relaciones humanas violentas es que lo propiamente humano son los sentimientos, y no las emociones. Para profundizar en ello nos vamos a basar en las contribuciones de Eric Kandel, premio Nobel de medicina o fisiología en el año 2000, y su obra Principles of neural science (Kandel et al, 2013), el principal texto internacional en neurociencia.

En ese libro, Eric Kandel dedica un capítulo entero, el cuarenta y ocho, a diferenciar entre emociones y sentimientos. Las emociones son

el conjunto de respuestas fisiológicas que ocurren más o menos inconscientemente cuando el cerebro detecta ciertas situaciones desafiantes, -en negativo y en positivo-. Estas respuestas automáticas ocurren tanto dentro del cerebro como en el cuerpo (Kandel et al, 2013, 1.079).

Esto se puede traducir, por ejemplo, en aumento del ritmo cardíaco, sudoración, tensión muscular, etc. y sucede inconscientemente. De forma diferente, los sentimientos "son la experiencia consciente de esos cambios en el cuerpo y en la mente" (Kandel et al, 2013, 1.079).

Los organismos más simples, como una célula bacteriana o la Aplysia, el molusco en el que Kandel realizó sus experimentos, tienen emociones, reaccionan a estímulos desafiantes en el entorno. Pero es obvio que ni la célula bacteriana ni la Aplysia tienen conciencia de esas reacciones, no las piensan, no les dan un significado. Por tanto, no tienen sentimientos.

Es la conciencia, ese maravilloso misterio que la psicología no ha llegado a desvelar, lo que nos distancia abismos de otros organismos. Reconocer que lo propiamente humano son los sentimientos y no las emociones es fundamental para superar la violencia. De no hacerlo, desde la inconsciencia de las emociones se pueden llegar a justificar las conductas más agresivas. Y, lo que es más importante, puesto que los sentimientos implican conciencia, se abre la posibilidad de revisarlos y cambiarlos, incluso sus emociones asociadas, si la persona así libremente lo escoge.

Por otro lado, la evidencia de que en los sentimientos hay conciencia, hay cognición, desmantela la supuesta oposición entre un hemisferio derecho que se dedica a la creatividad, a lo social y lo emocional, y un hemisferio izquierdo ocupado en lo analíico, lo matemático y lo racional. No existe tal oposición en el funcionamiento mental humano, es un neuromito con muy negativas consecuencias para la educación y el desarrollo humano (Howard-Jones, 2014). 
La neurociencia hace décadas que ha demostrado que las interacciones entre el encéfalo, el sistema límbico y las áreas neocorticales son numerosas y, a menudo, bidireccionales (Kandel et al, 2013). Dicho de otro modo, la emoción, el pensamiento y el cuerpo se afectan mutuamente siempre. Cuando una persona se deleita observando el ballet de Giselle o escuchando las cantatas de Bach, son áreas muy diversas de su cerebro, conectadas entre ellas, las que se activan. No hay sentimiento sin razón y esa es una excelente noticia para el ejercicio de la libertad.

Cuando las investigaciones internacionales señalan que los patrones de atractivo afectivo-sexual son aprendidos en la socialización es precisamente esta idea. Por mucho que las ocurrencias digan que el "amor es ciego" no lo es, la evidencia indica que las preferencias también en el ámbito afectivo y afectivo sexual son el resultado de la socialización individual y de la historia colectiva (Gómez, 2004, 2015). Que sea así es profundamente esperanzador, pues implica que esas preferencias se pueden cambiar, ser la persona quien decide quién le gusta y a quién escoge y no las tendencias sociales dominantes. Al implicar pensamiento, la persona puede reflexionar críticamente sobre sus sentimientos y emociones destructivas, si es el caso, y discernir y decidir cambiarlas hacia una dirección saludable, apasionada y libre, mejor para ella y para los demás.

La investigadora Lídia Puigvert de la Universidad de Cambridge ha demostrado esto empíricamente con el proyecto "Free Teen Desire" (Puigvert, 2015-2016) financiado en el marco del programa $\mathrm{H} 2020$ de la UE y orientado a la prevención de la violencia de género en la adolescencia. Uno de los estudios de ese proyecto, "Radical Love", fue desarrollado en colaboración con el Departamento de Psicología de la Universidad Loyola Andalucía. En él participaron estudiantes universitarias con una media de veinte años de edad; todas habían tenido relaciones afectivosexuales estables o esporádicas en las que habían sufrido algún tipo de violencia según la definición de violencia de género de la comunidad científica internacional.

Partiendo de las evidencias sobre el modelo de socialización dominante que vincula atracción y violencia, así como de los estudios sobre memoria autobiográfica, se partió de que la medida en que algunas mujeres jóvenes recuerden con cierta atracción relaciones afectivo-sexuales violentas es crucial para su vida. La razón, desde la psicología de la memoria, es que cuanto más se asocien esos recuerdos al deseo, más probable es que no se rompa la asociación aprendida entre la atracción y la violencia y, por tanto, que esas chicas procesen la información afectivo-sexual, sientan y tomen decisiones íntimas en consecuencia con esa asociación.

A través de la lectura del libro Radical Love (Gómez, 2004), que discute científicamente la naturaleza social del amor y la atracción y vacía de atractivo la violencia, 
las jóvenes que habían experimentado al menos una relación afectivo-sexual violenta pudieron recuperar dichos recuerdos y reflexionar críticamente sobre los mismos. Los resultados, en proceso de publicación, han sido sorprendentes.

Siguiendo esta misma línea, el proyecto de investigación MEMO4LOVE (RacioneroPlaza, 2017-2019) trabaja en la actualidad sobre el impacto de las Intervenciones de socialización preventiva de la violencia de género que promueven la reflexión crítica de alto nivel sobre los recuerdos autobiográficos en interacción con otras personas. La investigación trata incluso sobre una respuesta emocional que tenga como objetivo implícito vaciar la violencia de su atractivo y prevenir la violencia de género en la adolescencia, puesto que ésta supone cambios en la actividad cerebral, medida con registros electrofisiológicos.

La dimensión de conciencia, la posibilidad de reflexionar sobre los propios sentimientos, hace posible lo que Marcel Proust supo describir mejor que la evidencia: "El recuerdo de las cosas pasadas no es necesariamente el recuerdo de las cosas tal y como ocurrieron". Esas reconstrucciones de la memoria son fundamentales. La investigación en psicología de la memoria ya ha demostrado que solo es posible transformar los recuerdos que son accesibles a la conciencia (Cohen y Conway, 2008), así como ha señalado que la principal función de la memoria humana no tiene que ver con el pasado sino con el futuro. Recordamos nuestra vida para construir nuestra identidad y planificar nuestro futuro (Klein et al, 2010). En función de cómo recordamos el pasado, y cómo nos sentimos al recuperarlo, procesamos el presente e imaginamos nuevos horizontes.

Desde la conciencia, somos nosotros quienes decidimos cómo regular los recuerdos y sus sentimientos asociados; desde la conciencia, somos nosotras y nosotros quienes podemos decidir qué dirección dar al pasado para cumplir propósitos personales y acercarnos más al tipo de persona que deseamos ser y al tipo de vida que soñamos vivir. Mientras que si los recuerdos y los afectos no positivos permanecen en la base del iceberg, confinados a la inconsciencia, son ellos quienes nos podrían conducir hacia lugares que podrían incluso llegar a contradecir nuestros mejores sueños.

Esa conciencia, unida al tipo de personas que queremos ser, lo que Markus y Nurius (1986) han llamado "posible selves" (personas posibles), puede ser el inicio de una toma de decisiones que implique la elección de relaciones ausentes de violencia, igualitarias, saludables y apasionadas. La elección de esas relaciones dibuja trayectorias de desarrollo positivo que se vuelven contextos de libertad. 


\section{Las relaciones humanas de calidad mejoran la salud}

La investigación científica ya ha mostrado que las personas en relaciones humanas de calidad y, concretamente en relaciones afectivas positivas, tienen estados emocionales que favorecen una mejor salud general. Los estudios desarrollados por Peter Salovey desde la Universidad de Yale han arrojado muy relevante luz sobre esta cuestión (Salovey et al, 2000).

Otros estudios publicados en un nuevo ámbito de investigación denominado psicología positiva y de la felicidad, han evidenciado que las personas que tienen relaciones románticas saludables tendrán una mayor satisfacción con su propia vida a lo largo del tiempo (Dyrdal et al, 2011). Dicha satisfacción es una variable fundamental en la salud mental. Recordando al psicólogo clásico Erik Erikson (1959), al acercarnos al final de nuestras vidas, miramos atrás y hacemos una valoración profunda de la vida que hemos vivido. Sentirse satisfecho con la misma genera en la persona un sentimiento de integridad que le reconforta y da sentido. Sentirse insatisfecho, por el contrario, provoca desesperación.

Pero más allá de las percepciones subjetivas, multitud de estudios científicos publicados en las revistas de más impacto mundial, como Plos One, vienen demostrando que las personas con relaciones íntimas más felices muestran perfiles biológicos más saludables (Loving y Slatcher, 2013). Estar en una relación íntima de calidad se asocia con mayor felicidad subjetiva y menor densidad de materia gris dentro del estriado dorsal derecho (Kawamichi et al, 2016). Incluso se ha comprobado que ver fotografías de la persona con la que se tiene una relación íntima positiva disminuye la sensación de dolor, lo que se relaciona con los recuerdos y sentimientos evocados por la imagen $y$, esto, con el sistema de recompensa (Youngert et al, 2010). Además, la investigación ha identificado que las personas con relaciones positivas de amistad, de pareja, en la comunidad, etc., tienen una presión arterial ambulatoria más baja, mejor funcionamiento inmune y niveles de oxitocina más altos que explican incluso una cicatrización de las heridas más rápida (Simpson y Campbell, 2013).

Las relaciones de calidad también protegen de enfermedades mentales como la depresión. Un estudio longitudinal publicado en Plos One (Teo et al, 2013) con una muestra de más de 4.600 norteamericanos de entre 25 y 75 años indicó que aquellas personas con relaciones sociales de peor calidad tenían el doble de riesgo de sufrir depresión que las personas con relaciones sociales de gran calidad. Entre los diferentes tipos de relaciones sociales estudiadas, las personas en relaciones de pareja de baja calidad tenían más riesgo de sufrir depresión a medio plazo. 


\section{La amistad protege de la violencia y del estrés tóxico}

Todo lo anterior nos conduce a otra evidencia fundamental para la prevención y la superación de la violencia en las relaciones humanas. Lo explicaré en términos del padre de la escuela socio-cultural de la psicología, Lev Vygotsky. Igual que necesitamos la interacción social para alcanzar niveles superiores de desarrollo cognitivo (Vygotsky, 1980), necesitamos interacciones humanas de calidad para superar la violencia y proteger a quienes la sufren. Solas y solos no podemos

La travesía de Ulises de regreso a Ítaca no fue fácil; estuvo, como el desarrollo humano, llena de retos y desafíos. Solo no podría haber hecho frente al canto de las sirenas. Pero, en ese momento, le ataron al mástil y remaron más fuerte. Fue gracias a sus compañeros de viaje que logró su sueño. Con ellos sí fue posible.

Cuando las amistades son de calidad, pueden convertirse en factores protectores del desarrollo de forma permanente. La investigación científica ha demostrado empíricamente esta cuestión: las amistades de calidad protegen de la violencia y del estrés tóxico.

Estudios en psicología del desarrollo han evidenciado que las niñas y los niños que tienen un mejor amigo o mejor amiga, tienen menos riesgo de ser víctimas de "bullying" porque ese tipo de amistad defiende ante cualquier ataque (Mayes y Cohen, 2003). Se trata de lo que internacionalmente se conoce como "bystander intervention", el posicionamiento de los iguales siempre al lado de la víctima, y que ha demostrado ser una de las acciones más eficaces para la superación del "bullying" y otras formas de acoso.

En la adolescencia, el tipo de amistades que se escogen tiene un papel importantísimo en el desarrollo o evitación de conductas de riesgo. Estudios fronterizos en este sentido han demostrado con técnicas de resonancia magnética funcional que la calidad de las amistades modula la sensibilidad neural hacia conductas de riesgo (Telzer et al, 2015). Las amistades de baja calidad, en las que se prioriza la imagen y el prestigio social por encima de la solidaridad y el compromiso, moldean el cableado neuronal de forma que aumentan la atracción al riesgo. Por el contrario, las amistades de calidad hacen que nuestro cerebro procese las conductas de riesgo como menos gratificantes y significativas. Esto conduce a una menor presencia de esas conductas en los afectados por amistades de calidad. 


\section{Conclusión}

Pueden ser relaciones afectivas íntimas o pueden ser relaciones de amistad; lo que la evidencia científica demuestra es que las personas con mejores relaciones humanas tienen una vida mejor. Además de todos los datos expuestos, la evidencia más sólida disponible hasta el momento a este respecto en la psicología mundial la encontramos en la Universidad de Harvard. El Harvard Study of Adult Development $^{3}$ es el trabajo científico longitudinal en el tiempo más largo realizado hasta la fecha sobre qué variables psicosociales y biológicas desde la juventud predicen la salud y el bienestar cuando se alcanzan edades avanzadas. La investigación empezó en el año 1938 y comprende dos proyectos, el Grant Study y el Glueck Study. En el Grant Study participaron 268 graduados de Harvard de las promociones comprendidas entre el 1939 y el 1944. Todos acabaron sus estudios durante la segunda guerra mundial y muchos lucharon en la misma. El Glueck Study se compuso de $\mathbf{4 5 6}$ chicos que crecieron en las familias más pobres de los barrios más desfavorecidos de Boston.

El personal investigador del proyecto acudió a las casas de todos esos chicos, entrevistaron a sus padres, más tarde a sus esposas o compañeras e hijos, recogieron todos sus informes médicos, les hicieron escáneres cerebrales, análisis de sangre, etc., y así, a lo largo del tiempo hasta la actualidad. Algunos de los participantes se convirtieron en abogados, médicos, trabajadores de fábricas, etc. Uno incluso fue presidente de los Estados Unidos. Algunos cayeron en el alcoholismo, otros desarrollaron esquizofrenia, algunos subieron mucho en la escala socio-económica y a otros les ocurrió lo contrario. Actualmente se continúa recogiendo datos y, desde el 2015, se está llevando a cabo el Second Generation Study, en el que se examina el desarrollo de los hijos e hijas de esos participantes del primer estudio.

Los resultados de estos ochenta años de estudio longitudinal exhaustivo son contundentes. De entre todos los factores estudiados, las relaciones humanas de calidad son los mejores predictores de vidas más largas y felices, por encima de la clase social, el coeficiente intelectual y los genes. Las evidencias conseguidas demuestran que las relaciones humanas de calidad protegen a las personas de los desencantos de la vida, les ayudan a retrasar el deterioro cognitivo y físico propio de la edad y mejoran su salud general. Por ejemplo, el estudio ha encontrado que el nivel de satisfacción con las propias relaciones personales que se tiene a los cincuenta años predice más la salud física posterior que los niveles de colesterol en sangre. Las

${ }^{3}$ Más información sobre el Harvard Study of Adult Development y publicaciones resultantes en http:// www.adultdevelopmentstudy.org/ 
personas que estaban más satisfechas en sus relaciones a los cincuenta años son las más sanas de toda la muestra a la edad de ochenta años. Y, al contrario, los resultados demostraron que las relaciones que no son de calidad, como aquéllas en las que hay tensiones y conflictos, empeoraron en todos los casos la salud de los participantes.

Que las relaciones humanas de calidad, sean de amistad, íntimas o en la comunidad son contextos de salud y libertad en el desarrollo, es una maravillosa noticia científica repleta de posibilidad para la humanidad. Es la transformadora idea de plasticidad que ha recorrido todo este artículo y que fue planteada por primera vez por el nobel Santiago Ramón y Cajal, padre de la neurociencia moderna. En propias palabras de Cajal (1894): "toda persona, si se lo propone, puede ser escultora de su propio cerebro".

Podemos esculpir autobiografías llenas de sentido, salud y felicidad, si libremente escogemos y cultivamos relaciones humanas de calidad. Al hacerlo, no sólo mejoramos nuestra vida, sino que también somos mejores para los demás.

\section{Referencias bibliográficas}

American Psychological Association (2003) Ethical principles of psychologists and code of coduct. Incluyendo las enmiendas de 2010 y 2016. Obtenido de: http:// www.apa.org/ethics/code/

Araújo, J. P., Lourenço, P., Azevedo, A., Friões, F., Rocha-Gonçalves. F., Ferreira, A., y Bettencourt, P. (2009) "Prognostic value of high-sensitivity Creactive protein in heart failure: a systematic review": Journal of Cardiac Failure, 15 (3), 256-266.

Bierhaus, A., Wolf, J., Andrassy, M., Rohleder, N., Humpert, P. M., Petrov, D., Ferstl, R., von Eynatten, M., Wendt, T., Rudofsky, G., Joswig, M., Morcos, M., Schwaninger, M., McEwen, B., Kirschbaum, C., y NaWroth, P. P. (2003) "A mechanism converting psychosocial stress into mononuclear cell activation": Proceedings of the National Academy of Sciences of the United States of America, 100 (4), 1920-1925.

BlACKBURN, E., y Epel, E. (2017) The Telomere Effect: A Revolutionary Approach to Living Younger, Healthier, Longer, Nueva York, Grand Central Publishing.

BRUNER, J. (1974) Beyond the information given, Londres, George Allen \& Unwin Ltd. 
- (1990) Acts of meaning, Cambridge/Londres, Harvard University Press.

- (1996) The Culture of Education, Cambridge/ Londres, Harvard University Press.

BuKOWSKI, W. M., SIPPOLA, L. K., y NewCOMB, A. F. (2000) "Variations in patterns of attraction of same-and other-sex peers during early adolescence": Developmental psychology, 36 (2), 147.

Chapman, A., y Wyndham, J. (2013) "A human right to science": Science, 340, 6138, 1291.

Cohen, G., y Conway, M. (eds). (2008) Memory in the real world, Londres, Psychology Press.

Secretariado para la Justicia Social y la Ecología-Compañía de Jesús (2014) "La Promoción de la Justicia en las Universidades de la Compañía": Promotio lustitiae, 116.

Dalla Pozza, V., Di Pietro, A., Morel, S., y Psalla, E. (2016) Cyberbullying among young people. [Dirección general de políticas internas del departamento de políticas C: Derechos de los ciudadanos y asuntos constitucionales, libertades civiles, justicia y asuntos de interior], Parlamento Europeo.

Drossman, D. A. (2011) "Abuse, Trauma, and GI Illness: Is There a Link?": The American Journal of Gastroenterology 106, 14-25.

DUMAN, R. S. (2009) "Neuronal damage and protection in the pathophysiology and treatment of psychiatric illness: stress and depression": Dialogues in Clinical Neuroscience, 11 (3), 239-255.

Dyrdal, G. M., Røysamb, E., Nes, R. B., y Vitters $\varnothing$ J. (2011) “Can a Happy Relationship Predict a Happy Life? A Population-Based Study of Maternal Well-Being During the Life Transition of Pregnancy, Infancy, and Toddlerhood": Journal of Happiness Studies, 12, 947-962.

ERIKSON, E. H. (1959) "Identity and the life cycle: Selected papers": Psychological Issues, 1, 1-171.

EUROPEAN UNION AgenCy for Fundamental RIGHTS-FRA (2014) Victims of crime in EU: the extent and nature of support for victims, obtenido de: http://fra.europa.eu/en/ publication/2014/victims-crime-eu-extent-and-nature-support-victims 
FleChA, R., Soler, M., y Sordé, T. (2015) "Europe must fund social sciences": Nature, 520 (7581), 193-193.

GómEZ, J. (2004) El amor en la sociedad del riesgo. Una tentativa educativa, Barcelona, Hipatia.

- (2015) Radical Love: A Revolution for the $21^{\text {st }}$ century, Nueva York, Peter Lang.

HiRSt, W., y RaJARAM, S. (2014) "Towards a Social Turn in Memory: An Introduction to a Special Issue on Social Memory": Journal of Applied Research in Memory and Cognition, 3 (4), 239-243.

HowARD JONES, P. (2014) "Neurosience and education: myths and messages": Nature Reviews Neuroscience, 15, 817-824.

Kandel, E., Jessell, Th., Schwartz, J. H., Siegelbaum, St. A. y Hudspet. A. J. ( ${ }^{52012)}$ Principles of Neural Science [1981], Nueva York, McGraw Hill.

Kawamichi, H., Sugawara, S. K., Hamano, Y. H., Makita, K., Matsunaga, M., Tanabe, H. C., OGINo, Y., SaIto, S. y SAdAto, N. (2016) "Being in a Romantic Relationship Is Associated with Reduced Gray Matter Density in Striatum and Increased Subjective Happiness": Frontiers in psychology, 7(1763). DOI: 10.3389/fpsyg.2016.01763.

Klein, S. B.; Robertson, T. E., y Delton, A. W. (2010) "Facing the future: Memory as an evolved system for planning future acts": Memory and Cognition, 38 (1), 13-22. DOI:10.3758/MC.38.1.13.

KolvenbaCH, P. H. (2008) Discursos universitarios, Madrid, UNIJES.

LEVI-MONTALCINI (1988) "Biografical", en www.nobelprize.org

LOVING, T. J., y SLATCHER, R. B. (2013) "Romantic relationships and health", en SIMPSON, J. A., y CAMPBELL, L. (eds.) The Oxford Handbook of Close Relationships, 617-637, Nueva York, Oxford University Press.

Markus, H., y Nurius, P. (1986) "Possible selves": American Psychologist, 41 (9), 954-969.

MAYes, L. y Cohen, D. (2003) The Yale Child Study Center Guide to Understanding Your Child: Healthy Development from Birth to Adolescence, Nueva York, Little Brown \& Co. 
Moore, S. E., Norman, R. E., Suetani, S., Thomas, H. J., Sly, P. D. y Scott, J. G. (2017) "Consequences of bullying victimization in childhood and adolescence: A systematic review and meta-analysis": World Journal of Psychiatry, 7 (1), 60-76.

NACIONES UNIDAS (1994) Declaración sobre la eliminación de la violencia contra la mujer, Nueva York, 23-II-1994 (Resolución A/RES/48/104).

PUIGVERT, L. (2015-2016) Free_Teen_Desire. Transforming adolescents' desires through dialogue for relationships free of violence. Este proyecto recibió financiación del programa de investigación e innovación Horizonte 2020 de la Unión Europea en virtud del acuerdo de subvención Marie Sklodowska-Curie Nº 659299.

RACIONERO-PLAZA, S. (2017-2019) MEMO4LOVE. Interacciones sociales y diálogos que transforman recuerdos y promueven relaciones afectivo-sexuales libres de violencia en la adolescencia. Plan Nacional de I+D+i. Ministerio de Economía y Competitividad. Gobierno de España. Referencia: EDU2016-75370-R.

RAMÓNY CAJAL, S. (1894) "The Croonian Lecture: La fine structure des centres nerveux": Proceedings of the Royal Society of London, 55 (331-335), 444-468.

Rebellon, C. J., y MANASSE, M. (2004) "Do "bad boys" really get the girls? Delinquency as a cause and consequence of dating behavior among adolescents": Justice quarterly, 21 (2), 355-389.

Romero Rodríguez, J. J. (2007) "Misión de una universidad jesuita: retos y líneas de futuro": Revista de Fomento Social 62, 393-418.

Salovey, P., Rothman, A. J., Detweller, J. B., y Steward, W. T. (2000) “Emotional states and physical health": American Psychologist 55 (1), 110-121.

Seedat, S., Stein, M. B., Kennedy, C. M., y Hauger R. L. (2003) "Plasma cortisol and neuropeptide $Y$ in female victims of intimate partner violence": Psychoneuroendocrinology, 28, 796-808. 10.1016/S0306-4530(02)00086-0 [PubMed].

SIMPSON, J. A., y CAMPBELL, L. (eds.) (2013) The Oxford Handbook of Close Relationships, Nueva York, Oxford University Press.

Shonkoff, J. P., Garner, A. S., Siegel, B. S., Dobbins, M. I., Earls, M. F., McGuinn, L., PASCOE, J., y WOOD, D. L. (2012) "The Lifelong Effects of Early Childhood Adversity and Toxic Stress": Pediatrics, 129 (1), 232-246 
Telzer, E. H., Fullgni, A. J., Lieberman, M. D., Miernicki, M. E. y Galván, A. (2015) "The quality of adolescents peer relationships modulates neural sensitivity to risk taking": Social Cognitive and Affective Neuroscience, 10 (3) 389-398.

Teo, A. R., Chol, H., y Valenstein, M. (2013) "Social Relationships and Depression: Ten-Year Follow-Up from a Nationally Representative Study": Plos One8 (4): e62396.

UNICEF (2014) Hidden in plain sight: A statistical analysis of violence against children, Nueva York, UNICEF.

United Nations Statics Division (2015) World's Women 2015. Trends and Statics, Nueva York.

Valls, R., Puigvert, L. y Duque, E. (2008) "Gender violence amongst teenagers": Violence Against Women, 14 (7).

VYGOTSKY, L. S. (1980) Mind in society: The development of higher psychological processes, Cambridge (MA), Harvard University Press.

World Health Organization-who (2015) Adolescents: Health risks and solutions, obtenido de http://www.who.int/mediacentre/factsheets/fs345/en/

- (2013) Global and regional estimates of violence against women: prevalence and health effects of intimate partner violence and non-partner sexual violence, WHO Department of Reproductive Health and Research, London School of Hygiene and tropical Medicine, South African Medical Research Council.

Younger, J., Aron, A., Parke, S., Chatterjee, N., y Mackey, S. (2010) "Viewing Pictures of a Romantic Partner Reduces Experimental Pain": Involvement of Neural Reward Systems. PLoS ONE 5 (10) el3309. 